\title{
Notas sobre variação toponimica: co-ocorrência e concorrência de nomes de lugares no Brasil colonia
}

\author{
Notes on toponymic concurrence and competition \\ of place names in Brazil colony \\ Cezar Alexandre Neri Santos ${ }^{1}$ \\ Universidade Federal de Alagoas (UFAL) - Campus do Sertão \\ DOI: https://doi.org/10.5902/2176148542326
}

Resumo: Neste trabalho, descrevemos aspectos qualitativos relacionados a processos de variação toponímica em sincronias pretéritas. Para isso, valemo-nos de topônimos registrados em certidões de doações de sesmarias da capitania de Sergipe Del Rey datadas das primeiras décadas de contato interétnico entre colonos ibéricos e indígenas. Nesse contexto, dois modi nominandi passaram a coexistir no espaço geográfico: uma toponímia indígena preexistente e uma nova nomenclatura sob o signo ideológico do colonizador. Considerando a concorrência e a co-ocorrência de nomes de lugares, identificamos casos de sobreposição toponímica, mas também a incorporação, nos mapas e registros, de uma camada toponímica autóctone anterior ao processo de colonização.

Palavras-chave: Variação toponímica. Toponímia. Contato interétnico. Brasil Colônia.

Abstract: In this paper, we describe qualitative aspects related to toponymic variation in past synchronies. For that, we selected place names registered in documents concerning donation of lands of the captaincy of Sergipe Del Rey dated from the first decades of interethnic contact between Iberian colonizers and indigenous peoples. In that context, two naming systems started to coexist in the geographical space: a pre-existing indigenous toponymy and a new nomenclature under the colonizers' ideological sign. Considering the competition and concurrence of place names, we identified cases of toponymic change, but also of incorporation, in maps and records, of an indigenous layer prior to the colonization process. Keywords: Toponymic variation. Place names. Inter-ethnic contacts. Colonial Brazil.

1 Doutor em Língua e Cultura (UFBA). Coordenador do Grupo de Estudos em Filologia e Lexicologia (GELeFil), sediado no curso de Letras/Língua Portuguesa da UFAL-Campus do Sertão. Contato: neri.ufal@gmail.com 


\section{Introdução}

A partir dos contatos interétnicos entre colonos ibéricos e nativos no Brasil Colonial, dois modi nominandi passaram a coexistir (e concorrer) nesse espaço geográfico: uma toponímia indígena preexistente e uma nomenclatura sob o signo ideológico do colonizador. Considerando que documentos do período permitem registrar formas variantes de nomes de lugares, o objetivo desse trabalho constitui discutir aspectos relativos à variação toponímica em sincronias pretéritas, especialmente

Cezar sobre o Brasil colonial. Esse debate abrange procedimentos de coleta, Alexandre de codificação e de análise, para o qual tomamos nomes selecionados Neri Santos em certidões de doações de sesmarias da capitania de Sergipe Del Rey datadas entre 1594 e 1623.

Para cumprir esse objetivo, assinalamos fundamentos teórico-metodológicos relativos à Sociolinguística Histórica e à toponímia colonial brasileira, referenciados por Lass (2000), Montgomery (2007), Dick (2000; 2002), Antunes e Carvalhinhos (2007), Souza (2009), Santos (2012; 2019), dentre outros(as). Contextualizamos sócio-historicamente a fonte e o corpus do trabalho, com a descrição e a análise de formas variantes nos níveis grafo-fonológico e lexical. Com isso, aspectos geopolíticos e etnolinguísticos em um contexto de incipiente contato interétnico auxiliam a compreender a constituição da nomenclatura geográfica nacional.

\section{Processos de variação em signos toponímicos}

Em geral, nomes próprios de lugares apresentam um caráter perene e "constituem uma referência, quase sempre associada à história da localidade, que importa preservar como património cultural" (VERISSIMO, 2008, s. p.). Por servirem, primeiramente, à identificação geográfica, muitos os tomam homogeneamente como nomes com unicidade lexical e ortográfica. Contudo, como atesta o Instituto Brasileiro de Geografia e Estatística (IBGE), órgão oficial responsável pela coleta e pela sistematização de nomes geográficos no Brasil,

\footnotetext{
[...] muitos lugares têm mais de um nome; muitos nomes são repetidos, até num mesmo lugar; nomes podem ser escritos de mais de uma maneira; nomes locais podem ser diferentes dos nomes mais reconhecidos internacionalmente; nomes podem ser escritos em alfabeto não-romano, em alguns países (IBGE, 2008, p. 16).
} 
As propriedades listadas pelo IBGE (2008) destacam, portanto, um material linguístico heterogêneo. Dois processos têm sido examinados mais frequentemente: a flutuação gráfica - especialmente em nomenclatura de origem indígena ou africana; e a coexistência/concorrência de nomes para uma mesma localidade, dos quais um, geralmente, é a forma oficial e o(s) outro(s), forma(s) paralela(s), que pode(m), inclusive, ser mais disseminado(s) na comunidade do que aquela nomenclatura oficializada nos registros, planos e mapas oficiais. De acordo com Seabra (2016),

Os nomes de lugares, como parte integrante da língua usada por uma comunidade, estão sujeitos, como todos seus outros elementos, a variações decorrentes da hesitação de uso entre diversas formas de um mesmo vocábulo. Essas variações costumam ser de ordem analógica, fonética, morfossintática, lexical e, ainda, ocorrer nas chamadas reduções ou elipses (SEABRA, 2016, p. 144).
Notas sobre variação toponímica

Desse modo, identificamos a natureza diversificada desses processos. Frédéric Giraut (2019) afirma que a descrição de variantes toponímicas

[...] offer a rich interpretative potential, and can be considered through the prism of political and cultural geography as markers of the diversity of representations and practices. They can also reveal historical variations in people's relations to a given space and claims over this space ${ }^{2}$.

O tratamento desse rico material, por exemplo, numa perspectiva prescritiva, busca a fixação de uma das formas variantes por meio de uma política de oficialização e mesmo de correção de nomenclaturas geográficas ${ }^{3}$, muitas vezes promovidas por estudiosos de formação filológica, histórica e mesmo beletristas em geral. Assim ocorreu nas frequentes mudanças da toponímia municipal no país entre as décadas de 1930 e 1970, mormente produto de marcos legislativos que tentaram

2 “[...] oferecem um rico potencial interpretativo, e pode ser considerado pelo prisma da geografia política e cultural como marcadores da diversidade de representações e práticas. Elas também podem revelar variações históricas nas relações das pessoas quanto a um dado espaço e as afirmações em relação a esse espaço." (Tradução nossa).

3 Diversos estudos apresentam essa abordagem, dos quais citamos Barbosa (1980), que debate acerca da padronização ortográfica na toponímia brasileira no âmbito de nomes de lugares de origem tupi, a exemplo das variantes grafadas em <ss> ou em <ç> no elemento assu/açu, grande em tupi (Paraguassu Paraguaçu). 
uniformizar a nomenclatura, tendo gerado uma fase de co-ocorrência de formas anteriores e inovadoras. O público em geral, de certo modo, espera essa postura prescritiva e homogeneizante em relação aos nomes de lugares, o que pode ser explicado pela relação de pertencimento e de identidade e por crenças conservadoras - fenômeno denominado toponymic attachment por Kostanski (2016).

Em um polo distinto, a variação toponímica é encarada como um fenômeno dinâmico e social, cujos estudos não buscam uma hierarquiza-

Cezar Alexandre Neri Santos

\begin{abstract}
names or name systems are not to be understood as static, constant, or stable, but as variable and changing. In studies in toponymic competence it has been shown that very often some names are known to all speakers within the community, while other names are in use only among specific groups of speakers (AINIALA, 2016, p. 373-374).
\end{abstract}

Ainda de acordo com os estudos sociotoponímicos de Ainiala (2016), três variáveis costumam favorecer processos de variação toponímica: idade, profissão e gênero. Ou seja, idosos costumam conhecer mais denominações para uma localidade em relação a um(a) falante mais jovem; que a natureza de certas ocupações profissionais favorece a ciência de (nomes de) localidades, por exemplo, em relação a pessoas sedentárias; e que, a depender do grau patriarcal e da emancipação feminina em uma comunidade, indivíduos do sexo masculino podem, consequentemente, reconhecer topônimos com maior frequência.

A variação - e a mudança - são propriedades linguísticas que ocorrem tanto na língua falada quanto na escrita, que são ambas fontes de dados linguísticos. Este estudo, portanto, pela natureza do corpus, filia-se aos pressupostos da Sociolinguística Histórica, que “[...] tem como meta descrever e explicar os fenômenos de variação e mudança linguísticas em seu contexto social, cultural e histórico" (ROSA, 2015,

\footnotetext{
4 “Os nomes não são estáticos, constantes ou estáveis, mas variáveis e em mudança. Estudos de competência toponímica têm mostrado que muito frequentemente alguns nomes próprios são conhecidos por todos os falantes de uma comunidade, enquanto outros nomes próprios são usados apenas entre grupos específicos de falantes" (Tradução nossa).
} 
p. 8), valendo-se de corpora de modalidade escrita e considerando dimensões textuais, temporais, sociais, espaciais e de representatividade, como postulou Montgomery (2007, p. 121-124).

A seguir, valemo-nos das dimensões assinaladas por Montgomery (2007) para a descrição do corpus da pesquisa e apresentamos aspectos relativos à toponímia colonial, especialmente dos primeiros séculos de colonização.

\section{A toponímia colonial brasileira e o uso de fontes históricas na pesquisa toponímica}

As histórias territorial e toponímica do Brasil se assemelham àquelas de outros países compreendidos como parte do Novo Mundo - o continente americano, a Oceania e parte da África e da Ásia -, colonizados por metrópoles europeias. De acordo com Algeo (1988),

Notas sobre variação toponímica

Australia and America, although differing in numerous ways, share certain features of history, culture, and attitude. One of the historical similarities between the two lands was the sudden necessity facing the settlers of each to give names to a new landscape and to rapidly developing settlements (ALGEO, 1988, p. 173). ${ }^{5}$

Os locativos aborígenes australianos, por exemplo, equivalem aos topônimos em línguas de substratos indígenas no território brasileiro. Em ambos os casos, os colonos encontraram, para uma parcela do espaço geográfico, uma toponímia autóctone, restrita ao plano da oralidade. Esse contexto foi assim descrito por Antunes e Carvalhinhos (2007):

Em termos de apreensão de mundo, [... há] dois elementos que se refletiram na formação do sistema toponímico brasileiro: a apreensão do novo espaço e seus elementos (inéditos para o europeu como fauna e flora), descrevendo o que naquele momento era inominável em língua portuguesa, mas já possuía um termo em língua indígena e, por outro lado, descrevendo este espaço segundo a visão europeia, o que levaria à geração da duplicidade e possível superposição toponímica (ANTUNES; CARVALHINHOS, 2007).

5 “Austrália e América, embora diversas em várias questões, compartilham certas características históricas, culturais e de atitude. Uma das semelhanças históricas entre as duas terras foi a súbita necessidade que os colonos enfrentaram para dar nomes a uma nova paisagem e a núcleos de povoamento rapidamente erguidos" (Tradução nossa). 
Nesse contexto de supremacia ideológica, genocídio e glotocídio, modos diferentes de pensar e de viver, que implicam em distintos modos de nomear, foram postos em contato e, por vezes, em conflito. Assim, esse contato interétnico promoveu, na paisagem toponímica dos primeiros séculos de contato, dois vetores: a manutenção de uma toponímia nativa, em língua de substrato indígena, pela aceitação do grupo colonizador; ou a (re)nomeação de acidentes geográficos com topônimos dados por colonos, em língua portuguesa ou mesmo em uma língua

Cezar Alexandre Neri Santos geral indígena, sob o signo ideológico do colonizador ${ }^{6}$.

Quanto à manutenção de uma camada toponímica indígena pré-colonial e concorrente a incorporação pragmática de termos da fauna, da flora e outros aspectos físicos ou culturais à toponímia foi favorecida pela política de homogeneização linguística praticada pelos jesuítas por meio de uma língua geral tupi na costa brasílica (LEITE; FRANCHETTO, 2006). Isso relativiza o argumento de que o movimento colonial tão somente apagou a toponímia denominada pelos silvícolas, entendendo que, se houve uma camada toponímica que "[...] ignorava a camada indígena" (ANTUNES; CARVALHINHOS, 2007), houve também a aceitação e consequente inclusão desse tipo de nomenclatura, visto que o indígena se distinguia, especialmente, por poder denominar os elementos físico-naturais dessa nova terra.

$O$ registro perene desses elementos na nomenclatura geográfica dependia da tecnologia da escrita, desconhecida pelos silvícolas até então. Assim, o colono, com uma mentalidade burocrática, mercantilista e católica, mono ou mesmo bilíngue, tinha o poder denominativo, quem podia e devia batizar a nova terra ${ }^{7}$. A superposição toponímica caracterizava a mudança hegemônica para nomes de origem portuguesa, sendo a língua europeia um instrumento de propagação da Fé, da Lei e do Rei, parafraseando Gândavo (1576).

Assim, o achamento e a edição de documentos primários são valiosos para confirmar (ou não) hipóteses de naturezas linguística e extralinguística, sendo que o toponimista de abordagem linguístico-

6 Destacamos que o prestígio de um elemento linguístico muda diacronicamente, como é o caso de topônimos de línguas de substrato indígenas: enquanto no primeiro momento do processo de colonização, era comum a mudança da nomenclatura autóctone para signos em língua portuguesa, houve, ao menos dois momentos - meados do século XIX e meados do século XX -, em que registramos o incentivo para a formulação de topônimos de origem indígena no país (SANTOS, 2019).

7 Como advertem Antunes e Carvalhinhos (2007), "Mesmo sendo datados como dos primeiros séculos do Brasil Colônia, nem todos os topônimos hoje identificados como de origem tupi podem ser atribuídos a denominadores índios, pois, como já foi visto, a língua brasílica era falada tanto por índios quanto por portugueses, mamelucos e até africanos." 
-histórica deve "fazer bom uso de maus dados", tomando a reconhecida proposição de Labov (1982, p. 20) em relação ao tratamento de corpora datados e localizados. Quanto à importância do uso de corpora filologicamente tratados para o exame toponímico, Santos (2019) afirma que

[...] os estudos toponímicos podem (e devem) se valer de documentos como testemunhos linguísticos e históricos. A confiabilidade das informações é proporcional à segurança que os corpora podem oferecer. Para isso, requerem-se documentos fidedignos, datados e localizados - o que só é possível por meio de critérios filológicos bem definidos. O labor filológico, portanto, se estabelece como fundamental no estudo toponímico, pois, a partir de edições confiáveis cujo objetivo seja o de servir a estuNotas sobre variação toponímica dos linguísticos, pode-se dar um tratamento acurado a questões grafemáticas, morfossemânticas e outras no âmbito da variação e da mudança linguísticas (SANTOS, 2019, p. 461).

Na descrição de um corpus toponímico dos séculos XVI e XVII, podemos, por exemplo, caracterizar referentes do meio físico, a exemplo dos trabalhos de Alves (2002; 2005), que se valem de fontes históricas e cartográficas para a compreensão de Sergipe colonial. As marcas dos povos autóctones na toponímia configuram "rastros de uma civilização e de uma cultura que não conseguiu superar o confronto com os recém-vindos, sucumbindo ao peso de sua organização e de sua estrutura mais unitária" (DICK, 2002, p. 133, grifos do original). Registrados em documentos, em cartas e em mapas históricos, esses topônimos configuram importante quanto ao registro de variantes gráficas e lexicais e à dinâmica territorial e podem ser tomadas como material de análise da forma e do léxico de línguas minoritárias e da sócio-história colonial, como fósseis linguísticos (DICK, 1990, p. 25), envoltos de uma aura arqueológica.

Seabra (2016) atesta que "Apesar de não estarem imunes à variação, Dauzat [(1928)] acredita que para um estudo sobre épocas recuadas, os topônimos são os dados mais perfeitos e seguros, testemunhos de formações linguísticas desaparecidas" (apud SEABRA, 2016, p. 142). Como exemplo dessa conservação e importância no uso de fontes históricas, procedemos à descrição de formas variantes de alguns cursos d'água que banham o território sergipano. O rio São Francisco, por exemplo, era denominado Opará pelos índios tupi (MACHADO, 2009) e também 
Parapĩtinga (PEREIRA, 2020). Para o rio Vaza Barris, Pereira (2020) relata as seguintes variantes: "Potiiĩpeba; Potihypeba; Rio de Vazarbarries; R. Vazabazes; R. vasabaris; $\mathrm{R}^{\mathrm{o}}$ : vasabara:; Rio de Vazabaris; Rio de vazabarris; Cotegipe; Pitui; Pituhy; Irapiranga; Yrapiranga" (PEREIRA, 2020), das quais o corpus sesmarial deste trabalho atestou Irapiranga, Potipeba e Potegipe. Quanto ao rio Real, antes Hitanhy, Santos (2019) afirma que

os indígenas designavam o rio Real antes da colonização ibéri-

Cezar ca, como demonstra a carta de sesmaria de Cristovão de Rabello Alexandre Dazevedo, de 30 de maio de 1596: “[...] na baja do salvador q ele quer morar e viver no Rio do Hitanhi chamado pela nosa lingua Rio Real e trazer suas pesas pera o quoal não ten terras" (vide curso d'água, mas sendo superposta pelo topônimo Rio Real já nas primeiras décadas de colonização (SANTOS, 2019, p. 467).

Assim, sob certas circunstâncias, a não ocorrência de variantes em um corpus permite inferências tanto quanto os casos de ocorrência, podendo sugerir que signos toponímicos estavam em desuso, suplantados por nomenclaturas inovadoras, como foi o caso das variantes do rio São Francisco no período do registro das sesmarias sergipanas. Também atestamos processos de variação toponímica já na camada pré-europeia, permitindo inferir que etnias indígenas que se valiam de línguas diversas nomeiam o espaço diversamente, sob motivações independentes umas das outras. A seguir, descrevemos a fonte primária e analisamos como se apresentam os processos de variação toponímica no contexto colonial sergipano.

\section{Diversidade toponímica nos anos quinhentos e seiscentos em Sergipe del Rey}

o corpus toponímico deste trabalho data do início do processo de colonização do território sergipano. Após subjugarem os gentios locais, em 1590, a então Coroa luso-espanhola promoveu a fundação de uma estrutura administrativa em São Cristóvão, sede da capitania sergipense (FREIRE, 1891; SALOMÃO, 1996), necessitando de colonos para a efetivação posse do território. Com o fracasso majoritário do sistema de Capitanias Hereditárias, a Coroa estabeleceu o sistema sesmarial, de caráter perpétuo e hereditário, para o povoamento, a defesa e o apro- 
veitamento da terra, como exposto na documentação. A doação de sesmarias vigorou no Brasil até o fim do período colonial, no início dos anos oitocentos, cuja doação de glebas de terra era confiada pelo rei aos capitães-mores das capitanias (SILVA, 2008, p. 28-29).

Tais doações eram requeridas via cartas de sesmarias e atestadas em um livro de registro notarial. Como gênero de texto, essas cartas possuem uma estrutura fixa em forma de petição de benesses, evocada e repetida, cujos constituintes formais assim se configuram: na parte inicial, o protocolo apresenta invocação divina, intitulação, endereço e saudação; na parte medial, traz elementos como preâmbulo, notificação, narrativa, dispositivo, cláusulas finais, onde os topônimos são geralmente registrados, assinalando, especialmente a origem dos colonos e/ou a localização e os limites das glebas de terras requeridas; e, ao fim, um es-

Notas sobre variação toponímica catocolo, com a data e local do despacho, validação da petição e assinaturas do escrivão e do concessionário (SPINA, 1977, p. 56-57).

Os topônimos registrados nessas cartas sesmariais datadas entre 1594 e 1623 ilustram o processo inicial de povoamento colonial no território sergipano. A documentação está transcrita em Freire (1891). Mesmo com diversas omissões e incorreções (orto)gráficas (lapsi calami) na leitura paleográfica de nomes de acidentes geográficos, são dados autênticos sobre a forma de aproveitamento, os limites e extensões das glebas de terra, além da identificação daqueles acidentes físicos e daquelas povoações. Sua relevância se dá, em especial, por ter sido a única documentação de caráter oficial a ter resistido à invasão holandesa em Sergipe, na década de 1630 (FREIRE, 1891, p. 43), de modo que, sem sua salvaguarda, provavelmente não tomaríamos conhecimento de alguns topônimos datados do período pré-europeu e das primeiras décadas de colonização sergipana.

No processo de escritura desses manuscritos, entendemos que dois sujeitos têm papel ativo na representação gráfica de nomes geográficos: os sesmeiros, como requerentes das sesmarias, e os escrivães, que são os scriptores. Os sesmeiros da colônia brasileira eram "homens ligados à pequena nobreza em Portugal, ou militares e navegantes com títulos de vitória, que lhes asseguravam o mérito de uma recompensa "destinada a premiar serviços relevantes prestados à Coroa" (DIEGUES JR., 1959, p. 17), muitos dos quais, quando da petição, se encontravam em capitanias vizinhas, como Bahia de Todos os Santos, Pernambuco e Espírito Santo. Já aos escrivães, funcionários cartoriais, cabia a transcri- 
ção dos nomes relatados. Assim, tal qual na brincadeira infantil telefone sem fio, cujos ruídos de compreensão são diversos, também conjecturamos exemplos de má leitura quando das transcrições por parte daqueles scriptores, especialmente em se tratando de topônimos em línguas de substrato, tipologicamente diversas da gramática portuguesa ${ }^{8}$ (SAMPAIO, 1901; SOUZA, 2009). Em último grau, argumentamos que a flutuação gráfica pode estar relacionada a tais condicionantes.

Nessa documentação, há topônimos com uma única ocorrência, e

Cezar Alexandre Neri Santos outros que apresentam mais de uma dezena de ocorrências, como Cotinguiba, cujas variantes estão descritas em Mott (2008) e em Santos (2012). Os dados confirmam a existência de topônimos de procedência portuguesa e também indígena, notadamente de uma língua de base tupi (DICK, 2000), não tendo sido encontrados topônimos de origem africana ou de outras línguas nacionais europeias, como francês ou holandês. Estruturas toponímicas compostas por hibridismo também não foram encontradas, com exceção do próprio nome da capitania - Sergipe Del Rey, justificado por um contato interétnico ainda incipiente.

Os topônimos de línguas de substrato indígena totalizam cerca de quatro quintos do corpus (SANTOS, 2012), o que, mais uma vez, se justifica pelo contexto ainda embrionário de povoamento por parte dos colonos na capitania sergipana. Quanto à análise semântica, não foi possível decifrar a etimologia de uma parcela desses nomes nos dicionários de língua e em glossários toponímicos, como Guaraná (1916) e Cunha (1998), transformando esses signos linguísticos em oráculos semântico-históricos a serem futuramente tratados. Aqueles topônimos indígenas que tiveram seu(s) significado(s) recuperado(s) trazem como especificidade elementos físicos da localidade circunscrita, como a hidrografia, o relevo, a fauna e a flora, idiossincráticos aos europeus, sendo rico material linguístico do modus vivendi dos silvícolas. Já a nomenclatura em língua portuguesa aciona uma toponímia de homenagem - seja de santos e de santas do hagiológio católico, como São Francisco e São Cristóvão e Santa Catarina - e a estrutura colonial, como em Enforcados e Aldeia dos Padres.

As propostas de bancos lexicográficos devem considerar a diversidade toponímica em sincronia e em diacronia. A ficha lexicográfico-toponímica proposta por Dick (2004), por exemplo, possibilita o regis-

8 O fato de a ortografia portuguesa não ser uniforme naqueles séculos e, além disso, ainda configurar uma fase de transição entre características fonéticas e pseudoetimológicas (COUTINHO, 2005, p. 71 et seq.) também deve ser considerada para aqueles que busquem examinar formalmente esses signos. 
tro de variantes toponímicas e de denominações anteriores nos campos Informações enciclopédicas e Histórico. O corpus deste trabalho, tratado sob orientação linguístico-histórica, foi inventariado por Santos (2012), que adaptou a base lexicográfica de Dick (2004) e assinalou os seguintes campos: variante lexical, registro de lexemas variantes para um acidente geográfico; variante grafo-fonológica, registro de grafias flutuantes para um mesmo significante, auxiliando análises gramaticais, tal qual assinalado por Lass (2000); e fac símile: excerto do signo toponímico coletado na fonte manuscrita ou impressa obtido por meio fotomecânico. Ilustramos, no Quadro 1 que segue, essa proposição aplicando a um curso d'água que banha o município sergipano de Santa Luzia do Itanhy: o topônimo Aritiquiba ${ }^{9}$, com três ocorrências na documentação sesmarial.

Notas sobre variação toponímica

\section{Quadro 1 - Ficha lexicográfico-toponímica do rio Aritiquiba}

\begin{tabular}{|c|c|}
\hline Topônimo atual & Aritiquiba \\
\hline Elemento(s) genérico(s) & Rio / Esteiro \\
\hline Taxonomia & Fitotopônimo \\
\hline Variante(s) lexical(is) & Rio Guararema / Ibirarema / Bararema / Guarajahy \\
\hline Variante(s) grafo-fonológica(s) & Aretycutuba \\
\hline Provável origem linguística & Indígena (tupi) \\
\hline Versão(ões) etimológica(s) & $\begin{array}{l}\text { Araticu-ybá: árvore, pé de araticum, araticuzeiro } \\
\text { (GUARANÁ, 1916, p. 299) }\end{array}$ \\
\hline Fac símile & aneforsicto \\
\hline
\end{tabular}

Fonte: Adaptado de Santos (2012, p. 78; 94).

A ficha do Quadro 1 apresenta dados toponímicos referentes ao curso d'água contemporaneamente grafado Aritiquiba. O topônimo é formado pelo nome de uma árvore de grande porte da família Annonaceae, "da mesma família da atemóia, pinha, condessa, graviola, fruta-do-conde", o araticuzeiro (ARATICUM, 2020) e o sufixo tupi -yba, de acordo com a decomposição proposta por Guaraná (1916, p. 299). Referente frequente na toponímia nacional, em Sergipe, Araticum é nome de dois

9 Uma nota de Freire (1891, p. 364), referente à carta de Bartolomeu Fernandez, de 1600, afirma que se trata de um "[...] afluente do rio Real, junto à foz. Conserva o mesmo nome". 
povoados nos municípios sertanejos de Canindé de São Francisco e de Porto da Folha, parece ser inconteste que Aritiquiba é um fitotopônimo, considerando sua natureza semântica de origem vegetal.

Seguimos as recomendações de Lass (2000), para quem o linguista histórico deve discernir sobre a relevância de dados escritos para o estudo da variação e da mudança linguisticas. No plano sincrônico, o inventário de formas variantes permite compreender a representações grafo-fonológicas concorrentes à época, por vezes anteriores à fixação

Cezar Alexandre Neri Santos ortográfica. Diacronicamente, o registro fac-similar identifica processos grafêmicos e fono-morfológicos no signo toponímico: o item Aretycutuba pode, portanto, ser examinada num continuum até sua atual forma, a exemplo de: flutuação dos grafemas $<\mathrm{y}>\mathrm{e}<\mathrm{i}>\mathrm{e}<\mathrm{c}>\mathrm{e}<\mathrm{qu}>$; alteamento vocálico na segunda sílaba; síncope do fonema [t] no sufixo tupi -tyba, cuja diversidade gráfica está amplamente documentada:

\footnotetext{
[...] notamos a incerteza no que tange à verdadeira grafia de -iba, -uba, -tiba e -tuba. Devemos considerar primeiramente a indexação díspar de -YBA que, ao longo dos séculos, foi entendido e registrado como -i- ou -u-, ocorrendo o mesmo com -tyba em seus variantes -tiba, tuba, -diba e -duba. Para uma melhor sistematização sobre os geonomásticos é mister salientar que a pronúncia de /y/ sempre foi entendida ora [i], ora [u] (BRAGANÇA FILHO, 1999).
}

De acordo com Freire (1891, p. 405-406), em nota referente à carta de 1603 de Antonio Fernandes e de Francisco Dias, “Ariticuiba é o nome primitivo para o rio Guararema". Com isso, Freire (1891) propõe uma datação para as variantes toponímicas de origem indígena. Refletimos que deve haver cautela nesse tipo de proposição num contexto de parca documentação, visto que, nos mapas atuais, esses topônimos coexistem - nomes de dois rios no território sergipano distantes entre si cerca de 10 quilômetros ${ }^{10}$.

Ao discutirmos aspectos etnolinguísticos e sócio-históricos relacionados a processos de variação toponímica na toponímia colonial, procedemos às considerações finais.

10 Informação coletada em http://travelingluck.com/South+America/Brazil/Sergipe/_3461870_Rio+Guararema. html Acesso em: 30 jan. 2020. 


\section{Considerações finais}

O tratamento etnolinguístico de dados toponímicos das primeiras décadas de colonização do território brasílico permite (re)leituras linguístico-históricas e contribui para uma compreensão acerca dos processos de (re)nomeação de lugares. Motivada pelo inevitável contato interétnico, a co-ocorrência de topônimos se estabeleceu com relativa frequência. Destacamos que a língua e a cultura do colonizador se sobrepuseram em diversas situações, com o apagamento da nomenclatura autóctone, mas também identificamos a incorporação de uma nomenclatura autóctone, algumas das quais anteriores ao processo de colonização.

A documentação notarial monotestemunhal de petição e distribuição de terras entre as décadas de 1590 e 1620, diminuta em relação aos anos oitocentos e novecentos, assinala o primeiro corpus - e por vezes único - registro de vários signos toponímicos no território sergipano, alguns dos quais presentes nos mapas contemporâneos. Cientes da importância do tratamento filológico e das especificidades de coleta e de codificação de dados toponímicos pancrônicos, esperamos que os argumentos relacionados a processos de variação toponímica em sincronia pretérita possam contribuir para estudos diversos, nos quais os topônimos são material de análise ou ponto de intersecção.

\section{REFERÊNCIAS}

ALGEO, John. The Australianness of Australian Placenames. Names, vol. 36, n. 3-4, p. 173-186, 1988.

ALVES, Francisco José. Contribuição à Arqueologia de Sergipe Colonial. Revista do Instituto Histórico e Geográfico de Sergipe. v. 34, p. 39-53, 2005. . O rio São Francisco numa Carta Seiscentista. Canindé (MAX/ UFS). v. 2, p. 329-336, 2002.

AINIALA, Terhi. Names in society. In: HOUGH, Carole (Ed.) The Oxford Handbook of Names and Naming. Series: Oxford handbooks in linguistics. Oxford: Oxford University Press, p. 371-381, 2016. 
ANTUNES, Alessandra Martins; CARVALHINHOS, Patricia de Jesus. Toponímia brasileira. Origens históricas. In: XI Congresso Nacional de Linguística e Filologia, 2007, Rio de Janeiro. Cadernos do CNLF - Livro dos Minicursos. Rio de Janeiro: CiFEFil, 2007, vol. XI. Disponível em: http://www.filologia.org.br/xi_cnlf/. Acesso em: 13 jan. 2020.

ARATICUM. Cerratinga: produção sustentável e consumo consciente. Brasília. Disponível em: http://www.cerratinga.org.br/araticum/ Cezar Acesso em: 08 maio 2020.

Alexandre Neri Santos

BARBOSA, Rodolpho P.. Padronização de nomes geográficos no Brasil. Revista Brasileira de Geografia. v. 42, n. 1, p. 147-155, 1980.

BERG, Lawrence D.; VUOLTEENAHO, Jani. Critical Toponymies: The Contested Politics of Place Naming. Ashgate Publishing, Ltd., 2009.

BRAGANÇA FILHO, Álvaro Alfredo. A morfologia sufixal indígena na formação de topônimos do estado do Rio de Janeiro. In: II Letras em Foco - Semana de Letras \& Semana de Linguística e Filologia, 1999, Rio de Janeiro: UERJ (DEL) / CiFEFiL, 1999. Disponível em: http://www.filologia.org.br/pub_outras/sliit01/sliit01_29-48.html. Acesso em: 01 mar. 2020.

COUTINHO, Ismael de Lima. Gramática Histórica. 7. ed. 19. reimpressão. Rio de Janeiro: Ao Livro Técnico, 2005. 360p.

CUNHA, Antonio Geraldo da. Dicionário Histórico das Palavras Portuguesas de Origem Tupi. São Paulo: Melhoramentos; Brasília: Universidade de Brasília, 1998.

DICK, Maria Vicentina de Paula do Amaral. Rede de conhecimento e campo lexical: hidrônimos e hidrotopônimos na onomástica brasileira. In: ISQUERDO, Aparecida Negri; KRIEGER, Maria da Graça (Org.). As ciências do léxico. v. II. Campo Grande: EdUFMS, 2004, p. 121-130. . Contribuição do léxico indígena e africano ao Português do Brasil. In: Anais do Congresso Internacional de Lusitanistas, 2000. Disponível em: http://www.ebah.com.br/content/ABAAAAml4AG/contribuicao-lexico-indigenaafricano-ao-portugues-brasil. Acesso em: 02 mar. 2020. 
O português do Brasil no período colonial. In: Cadernos do CNLF (CiCEFil). Rio de Janeiro, v. V, 2002, p. 133-146. Disponível em: http://www.filologia.org.br/vcnlf/anais\%20v/civ6_13.htm. Acesso em 30 jan. 2020.

Toponímia e antroponímia do Brasil. Coletânea de Estudos. 2. ed. São Paulo: Serviço de Artes Gráficas da FFLCH/USP, 1990b. 224 p.

DIEGUES Jr., Manuel. População e propriedade da terra no Brasil. Washington DC: União Pan-Americana, 1959. variação toponímica

FREIRE, Felisbelo. História de Sergipe (1575-1855). Rio de Janeiro: Typographia Perseverança, 1891.

GANDAVO, Pero de Magalhães. Historia da prouincia Sãcta Cruz a qui vulgarmẽte chamamos Brasil. Lisboa: Officina de Antonio Gonsaluez, 1576. Disponível em: http://www.etnolinguistica.org/ biblio:gandavo-1576-historia

GIRAUT, Frédéric. Call for papers: Plural Toponymies. Multiple and Competing Place Names. 2019. Disponível em: https://neotopo. hypotheses.org/2184. Acesso em: 15 abr. 2020.

GUARANÁ, Armindo. Glossário Etimológico dos nomes da Língua Tupi na Geografia do Estado de Sergipe. Revista do Instituto Histórico e Geográfico de Sergipe, ano II, vol. II, nº 5, p. 297-326, 1916.

IBGE. Os aspectos relevantes dos nomes geográficos e os procedimentos de carga do BNGB - Banco de Nomes Geográficos do Brasil. Rio de Janeiro. Jul. 2008. Disponível em: <http://www.ngb. ibge.gov.br/App_Doc/APOSTILA_ASPECTOS\%20DA\%20COLETA\%20DE\%20 NOMES\%20GEOGRAFICOS_jUL2008_REVISADO_GRACIOSA_VITOR.pdf>

KOST ANSKI, Laura. Toponymic attachment. In: HOUGH, Carole (Ed.) The Oxford Handbook of Names and Naming. Series: Oxford handbooks in linguistics. Oxford: Oxford University Press, p. 412426, 2016. 
LABOV, William. Building on empirical foundations. Perspectives on historical linguistics. v. 24, 1982.

LASS, Roger. Historical linguistics and language change. Cambridge: Cambridge University Press, 2000.

LEITE, Yonne; FRANCHETTO, Bruna. 500 anos de línguas indígenas no Brasil. In: CARDOSO; Suzana Alice Marcelino; MOTA, Jacyra AnCezar drade; MATTOS E SILVA, Rosa Virgínia (Org.). Quinhentos Anos de Alexandre História Lingüística do Brasil. Salvador: Secretaria da Cultura e Turismo do Estado da Bahia, p. 15-62, 2006.

MONTGOMERY, Michael. Variation and historical linguistics. In: BAYLEY, Robert; LUCAS, Ceil. Sociolinguistic variation: theories, methods, and applications. Cambridge: Cambridge University Press, p. 110-132, 2007.

MOTT, Luiz Roberto de Barros. Vida social e cotidiano em 'Sergipe o novo' à época das visitações do Santo Ofício e das Cartas de sesmarias: 1591-1623. In: Sergipe Colonial e Imperial: Religião, Família, Escravidão e Sociedade: 1591-1882. São Cristóvão: EdUFS; Aracaju: Fundação Oviêdo Teixeira, 2008.

PEREIRA, Levy. BiblioAtlas - Biblioteca de Referências do Atlas Digital da América Lusa. Disponível em: http://lhs.unb.br/atlas/ Parap\%C4\%A9tinga_ou_Rio_de_S.Francifco. Acesso: 25 maio 2020.

ROSA, Eliane da. Sociolinguística Histórica. Revista de Letras. Curitiba, v. 17, n. 21, jul./dez. 2015, p. 1-17. Disponível em: https:// periodicos.utfpr.edu.br/rl/article/view/3178/2560 Acesso em: 10 maio 2020.

SALOMÃO, Liliam da Fonseca. A lenta penetração portuguesa no Brasil. O caso de Sergipe d'El Rey, território marginal. Cadernos UFSHistória. São Cristóvão: DHI/PDPH/EDUFS, 1996. p. 105-115.

SAMPAIO, Theodoro. Da evolução histórica do vocabulário geográfico no Brasil. In: Revista do Instituto Historico e Geographico de São Paulo, 1903, vol. VIII, p. 150-158. Disponível em: <http:// biblio.etnolinguistica.org/sampaio-1903-evolucao>. 
SANTOS, Cezar Alexandre Neri. Contribuições da linguística histórica aos estudos toponímicos brasileiros. MACABÉA: Revista Eletrônica do Netlli, Crato, v. 8., n. 2., 2019, p. 453-472.

De Cirigype a Sergipe Del Rey: os topônimos nas cartas de sesmarias (1594-1623). Dissertação (Mestrado em Letras). São Cristóvão, 2012. 191 f.: il.

SEABRA, Maria Cândida Trindade Costa de. Variação e Mudança Notas sobre linguística de topônimos. In: Daniela COSTA; Dayme BENÇAL. (Org.). variação Nos caminhos do léxico. Campo Grande: Editora UFMS, 2016, v. toponímica 1, p. 137-154.

SILVA, Lígia Osório. Terras devolutas e latifúndio. Campinas: EdUNICAMP, 2008.

SOUZA, Genésio Seixas. Aspectos lexicais no manuscrito "Notícia do Brasil" de Gabriel Soares de Sousa. In: Anais da ABRALIN. Vol. 2, 2009, p. 3646-3651. Disponível em: http://www.leffa.pro.br/tela4/ Textos/Textos/Anais/ABRALIN_2009_vol_2/PDF-VOL2/Microsoft\%20 Word\%20-\%20Gen\%C3\%A9sio\%20Seixas\%20Souza.pdf.

SPINA, Segismundo. Introdução à Ecdótica. São Paulo: Cultrix/ EDUSP, 1977. 
